\title{
Incidence, Presentation, Characteristics and Short Term Outcomes of Hospitalized Pregnant Women Confirmed SARS-COV-2 Positive
}

\author{
Maheen Irshad ${ }^{1}$, Luna Nasry ${ }^{1}$, Ala Addin Sid Ahmed ${ }^{1}$, Lana Abdole ${ }^{1}$, Federico Mariona ${ }^{2}$ \\ ${ }^{1}$ Wayne State University School of Medicine, Detroit, Michigan USA \\ ${ }^{2}$ Michigan Perinatal Associates, Beaumont Health Dearborn, Michigan USA
}

\section{Email address:}

maheen.irshad96@gmail.com (M. Irshad), Inasry@atsu.edu (L. Nasry), alaasidahmed93@gmail.com (A. A. S. Ahmed), labdole@umich.edu (L. Abdole), fmariona@att.net (F. Mariona)

\section{To cite this article:}

Maheen Irshad, Luna Nasry, Ala Addin Sid Ahmed, Lana Abdole, Federico Mariona. Incidence, Presentation, Characteristics and Short Term Outcomes of Hospitalized Pregnant Women Confirmed SARS-COV-2 Positive. Journal of Gynecology and Obstetrics.

Vol. 9, No. 3, 2021, pp. 84-91. doi: 10.11648/j.jgo.20210903.16

Received: May 19, 2021; Accepted: June 19, 2021; Published: June 28, 2021

\begin{abstract}
To report the incidence, presentation, characteristics and outcomes of a cohort of hospitalized pregnant women who had tested positive for SARS-2, whether or not they had demonstrated signs of Coronavirus Disease-19 (2019-nCov, or Covid-19, ICD-10 U07.1). Material and Methods. The study includes pregnant women, 18 years old and older, who were hospitalized for evaluation or delivery and who had tested positive for SARS-CoV-2 via NP sampling. All were followed by RT PCR and NAA determination between March and December of 2020. Universal testing for SARS-CoV-2 was used throughout the study period. Maternal history and physical screening were conducted upon admission to detect any of the known variables of Covid-19, such as: fatigue, fever $(38 \mathrm{C})$, shortness of breath, and cough. Chest imaging was obtained when indicated. The screening process included domestic or international travel. Additional information collected on $100 \%$ of the patients included: maternal ethnicity, body mass index, and 5-digit zip code of maternal residence. Neonates (NN) from SARS-2 positive mothers at delivery admission were tested following the Neonatology service protocol, at age 24 and 48 hours. Additional testing was performed prior to NN discharge when indicated. Results. Of the 3,109 pregnant women who were hospitalized and tested during the study period, $4.3 \%$ were reported SARS-2 positive. Of these patients, 13.6\% were symptomatic for Covid-19 upon admission; 54\% showed a comorbidity; $61 \%$ were obese; and one patient needed mechanical ventilation. Table 1 summarizes the cohort characteristics. Table 2 shows the characteristics of the symptomatic women and their clinical course. Conclusion. Our report describes a pregnant patient cohort that had experienced mild to moderate Covid-19 disease. Conflicting studies postulated that pregnant women exposed to SARS-CoV-2 may suffer more serious adverse effects than their non-pregnant counterparts. In view of the wide spectrum of clinical events and the variable severity reported in association with Covid-19 in pregnancy, we believe that quality big data would be beneficial. We therefore recommend strict identification of maternal ethnicity, comorbidities, timing, acuity and severity of the disease. Moreover, health care culture with accurate harmonization of clinical findings and treatments via widespread collaborative efforts, with timely reporting, may assist in understanding the variable pathophysiology of the novel SARS-CoV-2, including its variants, and their conflicting effects on pregnancy.
\end{abstract}

Keywords: SARS-CoV-2, Covid 19 Disease, Pregnancy, Vertical Transmission, High Risk Pregnancy, Pandemic

\section{Introduction}

This novel human-to-human highly transmissible nano vector was first reported in early Fall 2019 in the Far East as the cause of a "pneumonia of unknown origin", later called Corona Virus Disease-19 (Covid-19). This was followed by rapid global spread. The World Health Organization (WHO) declared it an international health emergency on January 30 , 2020, and a pandemic on March 11, 2020.

Pregnant women are also affected by this novel viral pathogen. As the year 2020 progressed, a plethora of information became available on the subject. Compared to 
other populations at significantly increased risk of Covid-19 disease, the data suggest that pregnant women may not be affected with severe maternal morbidity, adverse perinatal outcomes, or the possibility of vertical transmission.

Clinical management guidelines associated with the treatment of Covid-19 in pregnancy were periodically published and updated by the World Health Organization (WHO), the International Federation of Gynecology and Obstetrics (FIGO), the Centers for Disease Control and Prevention (CDC), and other national organizations dealing with maternal care. In the United States, the American College of Obstetricians and Gynecologists (ACOG) and the Society for Maternal Fetal Medicine (SMFM) provided periodic statements in association with the clinical events and treatments of this highly transmissible coronavirus. As stated under objectives (vide supra) the purpose of the study is to ascertain the interaction between the viral infection and the women's pregnancy status. The significance of Covid-19 is demonstrated by the bibliographic volume that we are witnessing as a world wide effort to elucidate the variable pathogenicity of the virus, with especial attention on the effects on pregnant women and their offspring.

For further background on this novel pathogen's significant characteristics, we refer the reader to the extensive basic science literature that is readily accessible [1-3].

Table 1. Cohort characteristics.

\begin{tabular}{|c|c|c|}
\hline Maternal age (years) & Range 18-52 & Median 26.5 \\
\hline 1. $18-24$ & 47 & \\
\hline 2. $25-34$ & 70 & \\
\hline 3. $35-44$ & 33 & \\
\hline 4. $>45$ & 2 & \\
\hline SARS-CoV-2 positive by PCR & $148(4.72)$ & \\
\hline \multicolumn{3}{|l|}{ Ethnicity } \\
\hline 1. Black & $48(32.6 \%)$ & \\
\hline 2. White & $23(15.6 \%)$ & \\
\hline 3. Middle East & $53(35.3 \%)$ & \\
\hline 4. Hispanic & $23(15.6 \%)$ & \\
\hline 5. Other & $6(5 \%)$ & \\
\hline \multirow[t]{2}{*}{ Body Mass Index $\left(\mathrm{K} / \mathrm{m}^{2}\right)$} & Range & Median \\
\hline & 15.8 to 62.5 & 36.3 \\
\hline $\mathrm{BMI}>30 \mathrm{~K} / \mathrm{m}^{2}$ & $75(61 \%)$ & \\
\hline 1. Black & $24(32 \%)$ & \\
\hline 2. Middle East & $23(30 \%)$ & \\
\hline 3. White & $17(23 \%)$ & \\
\hline 4. Hispanic & $11(15 \%)$ & \\
\hline Covid-19 Asymptomatic & $131(88.4 \%)$ & \\
\hline Covid-19 Symptomatic & $17(11.5 \%)$ & \\
\hline Admission Comorbidities & $97(78.8 \%)$ & \\
\hline 1. Black & $32(26 \%)$ & \\
\hline 2. White & $18(14.6 \%)$ & \\
\hline 3. Middle East & $26(21.1 \%)$ & \\
\hline 4. Hispanic & $15(12.1 \%)$ & \\
\hline Other & $6(4.8 \%)$ & \\
\hline \multicolumn{3}{|l|}{ Admission COVID-19 symptoms } \\
\hline 1. Shortness of breath & $16(13 \%)$ & \\
\hline 2. Cough & $12(75 \%)$ & \\
\hline 3. Fever & $6(37.5 \%)$ & \\
\hline 4. Nausea, vomiting & $4(25 \%)$ & \\
\hline \multicolumn{3}{|l|}{ 5. Diarrhea } \\
\hline 6. Headache & $4(25 \%)$ & \\
\hline 7. Positive & $2(12.5 \%)$ & \\
\hline 8. chest imaging & $10(62.5 \%)$ & \\
\hline Lymphopenia $<20 \%$ lymphs) & $65(56 \%)$ & \\
\hline Thrombopenia $<100,000 / \mathrm{ml}$ & $4(3.47 \%)$ & \\
\hline \multicolumn{3}{|l|}{ Respiratory support } \\
\hline 1. Mechanical ventilation & $1(0.86 \%)$ & \\
\hline 2. Nasal cannula & $6(4.3 \%)$ & Max. $15 \mathrm{~L} / \mathrm{min}$ \\
\hline \multicolumn{3}{|l|}{ Delivery route } \\
\hline 1. Vaginal & $93(63.2 \%)$ & \\
\hline 2. Cesarean & $45(30.6 \%)$ & \\
\hline \multicolumn{3}{|l|}{ Delivery gestational age } \\
\hline 1. $\geq 37$ weeks & $95(83 \%)$ & \\
\hline 2. $<37$ weeks & $14(12 \%)$ & \\
\hline Maternal Length of stay (days) & & Mean \\
\hline 1. Prenatal & 41 & 2.56 \\
\hline 2. Delivery/Post-partum & 39 & 2.6 \\
\hline
\end{tabular}




\section{Material \& Methods}

This is a contemporaneous limited cohort observational descriptive study utilizing prospectively collected medical records via the institution's electronic medical record system, which provides maternal and short-term neonatal information. No a priori sample size calculations were conducted due to the limited size of the cohort. Descriptive statistics are reported in crude numbers and percentages, chi square obtained when appropriate, (Table 1).

All pregnant women 18 years old or older, evaluated and admitted to a single urban-suburban community general teaching hospital during the period of March 24 to December 31, 2020 who tested positive for SARS-CoV-2 by nasopharyngeal swab and subsequent reverse transcriptasePolymerase Chain Reaction (RT-PCR) nucleic acid amplification (NAA), were included. Universal testing was utilized during the study period.

Beaumont Dearborn is representative of birthing centers in the USA. It is located in Wayne County Michigan, an area that was reported as one of the hardest hit in the country by the pandemic. To protect the patients, families, other patients, newborns and hospital personnel, the hospital implemented universal SARS-CoV-2 testing on all pregnant women upon admission for inpatient care, including antepartum, labor, delivery and postpartum.

Table 2. Characteristics of the symptomatic SARS-CoV-2 positive patients.

\begin{tabular}{|c|c|c|c|c|c|c|c|c|c|c|c|}
\hline $\begin{array}{l}\text { AGE } \\
\text { (years) }\end{array}$ & Ethnicity & $\begin{array}{l}\text { BMI } \\
\mathrm{K} / \mathbf{m}^{2}\end{array}$ & Comorbidity & $\begin{array}{l}\text { First evaluat } \\
\text { (weeks) } \\
\text { Symptoms } \\
\end{array}$ & Meds & $\begin{array}{l}\text { Delivery } \\
\text { (weeks) }\end{array}$ & $\begin{array}{l}\text { BIRTH } \\
\text { ROUTE }\end{array}$ & $\begin{array}{l}\text { Respir } \\
\text { Support }\end{array}$ & $\begin{array}{l}\text { ICU } \\
\text { admit }\end{array}$ & $\begin{array}{l}\text { LOS\#1 (days) } \\
\text { LOS \#2 (days) }\end{array}$ & Disposition \\
\hline 26 & B & 48,1 & Obese & $\begin{array}{l}23 \text { Cough SoB } \\
\text { Fever }\end{array}$ & $\begin{array}{l}\text { AZT HCQ REM } \\
\text { Steroids }\end{array}$ & 39.3 & VD & $\begin{array}{l}\text { High Flow } \\
\text { Nasal cannula }\end{array}$ & No & 72 & Home \\
\hline 38 & B & 38.4 & Obese & $\begin{array}{l}24 \text { Cough SoB } \\
\text { Fever }\end{array}$ & $\begin{array}{l}\text { AZT HSQ Steroids } \\
\text { Lovenox }\end{array}$ & $\mathrm{X}$ & $\mathrm{X}$ & Nasal cannula & No & $6 \mathrm{X}$ & $\begin{array}{l}\text { Home Lost } \\
\text { to } \mathrm{f} / \mathrm{u}\end{array}$ \\
\hline 30 & $\mathrm{ME}$ & 36.7 & $\begin{array}{l}\text { Obese Ch } \\
\text { HTN GDMA } \\
\text { Anxiety }\end{array}$ & $\begin{array}{l}28 \text { Cough SoB } \\
\text { Fatigue }\end{array}$ & AZT HCQ Heparin & 39 & $\begin{array}{l}\text { Failed ECV } \\
\text { CS }\end{array}$ & Nasal cannula & Yes & 53 & Home \\
\hline 35 & W & 36.2 & $\begin{array}{l}\text { Obese } \\
\text { Diabetes }\end{array}$ & 32 Cough SoB & AZT HCQ & $\begin{array}{l}\text { PPROM } \\
37.2\end{array}$ & NR-FHR CS & & No & 13 & Home \\
\hline 26 & $\mathrm{ME}$ & $\begin{array}{l}36,2 \\
4\end{array}$ & $\begin{array}{l}\text { Obese PICOS } \\
\text { Hypothyr }\end{array}$ & $\begin{array}{l}35 \text { SoB Pulm } \\
\text { Embolism }\end{array}$ & Heparin & 37.2 & Sched IoL VD & & No & 41 & $\begin{array}{l}\text { Home on } \\
\text { heparin }\end{array}$ \\
\hline 24 & $\mathrm{H}$ & $\begin{array}{l}42.2 \\
7\end{array}$ & Obese & $38.6 \mathrm{Na}$, Vo & Antiemetic Hydrate & 40.5 & VD & & No & 21.5 & Home \\
\hline 23 & $\mathrm{~B}$ & $\begin{array}{l}26.6 \\
7\end{array}$ & $\begin{array}{l}\text { Chr kidney } \\
\text { Disease }\end{array}$ & $\begin{array}{l}31.2 \mathrm{SoB} \\
\text { Hypoxia }\end{array}$ & REM Steroids & $\begin{array}{l}\text { In labor } \\
31.6\end{array}$ & VD & Nasal cannula & No & 53 & Home \\
\hline 35 & B & 37.4 & Obese Asthma & 29 SoB Cough & Hydrate & 37.4 & VD & & No & 02 & Home \\
\hline 34 & B & 44.3 & $\begin{array}{l}\text { Obese Asthma } \\
\text { GDMA }\end{array}$ & $\begin{array}{l}30.5 \mathrm{SoB} \\
\text { Pneum }\end{array}$ & Quarantine & $\begin{array}{l}31 \text { Resp } \\
\text { failure }\end{array}$ & $\begin{array}{l}\text { Resp failure } \\
\text { Emergency } \\
\text { RCS/TL }\end{array}$ & $\begin{array}{l}\text { ARDS ET } \\
\text { Mechan } \\
\text { ventilat }\end{array}$ & Yes & 1.510 & Home \\
\hline 29 & $\mathrm{~W}$ & 35.7 & Obese Asthma & $\begin{array}{l}38 \text { SoB Fever } \\
\text { Cough }\end{array}$ & $\begin{array}{l}\text { Albuterol IV } \\
\text { steroids Lovenox }\end{array}$ & 38 & VD & Nasal cannula & No & 32 & Home \\
\hline 23 & $\mathrm{H}$ & 29.4 & & $\begin{array}{l}40 \mathrm{Na} \text { Vom } \\
\text { Diarrh }\end{array}$ & Hydrate & 40 & VD & & No & 01 & Home \\
\hline 27 & B & 35 & Obese & $\begin{array}{l}37.3 \mathrm{Ha}, \mathrm{Na} \\
\text { Vom }\end{array}$ & Hydrate & 37.3 & Sched CS/TL I & Di/di twins & No & 02 & Home \\
\hline 30 & $\mathrm{ME}$ & 51.7 & $\begin{array}{l}\text { GDMA Obese } \\
\text { Poor PNC }\end{array}$ & 39.5 SoB & Glyburide & 39.5 & NR_FHR CS & & No & 03 & Home \\
\hline 19 & B & 36.3 & $\begin{array}{l}\text { Obese } \\
\text { Preeclampsia } \\
\text { Asthma }\end{array}$ & $\begin{array}{l}38.5 \mathrm{HA} \mathrm{Na} \\
\text { Vom. }\end{array}$ & $\begin{array}{l}\text { Misoprostol } \\
\text { Hydralazine } \mathrm{Mg} \\
\text { Sizine }\end{array}$ & 38.5 & Failed IoL CS & & No & 13 & Home \\
\hline 24 & $\mathrm{ME}$ & 27.4 & & $32 \mathrm{SoB}$ & BMTZ AZT Clinda & $\begin{array}{l}\text { PPROM } \\
32\end{array}$ & VBAC & & No & 13 & Home \\
\hline 27 & $\mathrm{~B}$ & 34 & Obese SC trait & $\begin{array}{l}30 \text { SoB Fever } \\
\text { fatigue }\end{array}$ & Hydrate & UNDEL & UNDEL & & No & 5 UNDEL & Home \\
\hline 41 & $\mathrm{H}$ & 26.5 & $\begin{array}{l}\text { Anxiety } \\
\text { GERD }\end{array}$ & $\begin{array}{l}33 \text { Cough } \\
\text { SOB T+ } \\
\text { Pneum }\end{array}$ & $\begin{array}{l}\text { Azithromycin } \\
\text { Steroids Lovenox }\end{array}$ & UNDEL & UNDEL & Nasal cann & No & 9 UNDEL & Home \\
\hline
\end{tabular}

B. Black W. White ME. Middle East H. Hispanic.

SoB: Short of Breath. ECV: External Cephalic Version. CS: Cesarean. VBAC: Vaginal Birth After Cesarean. Sched IoL: Scheduled induction of labor. PPROM: Premature Rupture of Membranes. ARDS: Acute Respiratory Distress Syndrome. ChHTN: Chronic hypertension. ICU: Intensive Care Unit. GDMA: Gestational diabetes mellitus. BMTZ: Betamethasone. UNDEL: Undelivered. LOS: length of stay. SC Trait: Sickle Cell Trait.

All patients were screened using a questionnaire which included fever $\left(100.4^{\circ} \mathrm{F}, 38^{\circ} \mathrm{C}\right)$, dry cough, shortness of breath, malaise, lack of taste or smell, nausea, vomiting and diarrhea in addition to history of recent close contact with a known affected person who was documented positive for SARS CoV-2 elsewhere or traveled through or from known 
affected areas. The patients that showed one or more of the symptoms listed were considered "symptomatic" (table 2). Gestational age was determined by obstetric ultrasound performed prior to admission or, if not available or discordant with the clinical findings, an obstetrical ultrasound was obtained at the time of the index admission.

All patients were treated by their attending obstetricians, internists, maternal fetal medicine physicians and multidisciplinary consultants as required. There was no standard Infectious Disease therapeutic protocol during the period of the study. We utilized the mild, moderate, severe and critical definitions when referring to the clinical status of Covid19 [4].

The subjects included in the study are not presented sequentially in order to decrease the chance of patient identification; no particular order has been followed in the patients' description in order to additionally protect their identity. Following the full record abstraction by study team members the patients were assigned a code number and deidentified.

Those patients scheduled for delivery or admitted in active labor were cared for in the Labor \& Delivery (L\&D) unit. Patients who were scheduled for labor induction or cesarean delivery were tested between 24 and 48 hours prior to admission in an outpatient curbside drive through.

All neonates were evaluated by the neonatologist or the attending pediatricians as the case indicated. Neonates from SARS-CoV-2 positive mothers were tested within 24 hours of life, unless testing was declined by the mother. Institutional Review Board (IRB) approval was obtained (2020-173 ref\#035713). No funding was available for the study.

\section{Results}

Between March and December of 2020, 3109 pregnant women were hospitalized, treated, followed up or delivered. 148 subjects were SARS CoV-2 positive (4.72\%). 2962 patients were SARS-CoV-2 negative. The institution uses universal testing for SARS-CoV-2 in hospitalized pregnant women. Seventeen subjects (11.5\%) were symptomatic, $76.4 \%$ in this group were admitted with respiratory symptoms.

Eighty six percent $(86 \%)$ of the patients were asymptomatic and admitted for reasons other than suspected SARS-CoV-2 The maternal cohort characteristics and demographics are shown on table 1. Gestational age at the time of the first presentation and SARS-CoV-2 positive testing ranged between 8 to $415 / 7$ weeks.

Ethnicity, civil status, body mass index (BMI) and 5-digit zip code of maternal residence were recorded on all patients. There were 33 different zip codes; $38 \%$ of the patients resided on the same zip code and clustered in a small geographic area.

At least one preexisting condition was demonstrated in 97 patients $(78.8 \%)$. The most common diagnosis was gestational diabetes with or without use of insulin (24\%), bronchial asthma in $14 \%$ and hypertension in $10 \%$. Black patients demonstrated comorbidities in $26 \%$, White patients in $14.6 \%$, Middle East patients in $21 \%$ and Hispanic patients in $12 \%$. $(\mathrm{p}=0.047)$.

Maternal obesity $\left(\mathrm{BMI} / \mathrm{Km}^{2}>30\right.$ range 15 to $62.5 \mathrm{~K} / \mathrm{m}^{2}$ ) was present in 75 patients $(61 \%)$ and distributed across ethnicities. Black 32\%, ME 30\%, White 23\%, Hispanic 15\%.

Two patients were lost to follow up after their initial evaluation, treatment and discharge, 1 patient was transferred to her attending physician in a different center; there were three early abortions and one ectopic pregnancy. Four patients remain undelivered.

Patient presentation:

Seventeen patients were symptomatic for Covid-19 disease on admission (11.5\%). Cough and shortness of breath were the most frequent signs, nausea and vomiting followed. $76.4 \%$ of the patients in this group were obese.

Nine patients in this group $(56.2 \%)$ were admitted, evaluated, treated and discharged to continue prenatal care via telehealth. Their combined prenatal length of stay was 30 days (range 1 to 7 ). Eight patients were later readmitted (range 0.5 to 16 weeks) for delivery with no signs of Covid19 disease. One patient was lost to follow up.

Six patients in this symptomatic group were delivered on the index admission.

Two patients had a temperature of $101.3^{\circ} \mathrm{F}$ on admission with evidence of PPROM; they were both diagnosed with chorioamnionitis, treated with intravenous antibiotics and delivered.

The vaginal delivery rate in the symptomatic group was $50 \%$, the total cesarean rate in the symptomatic group was $35.2 \%$. A summary of the symptomatic patients' outcomes is presented on table 2 .

130 patients $(88.4 \%)$ were asymptomatic on admission and remained so during their hospitalization which included labor, delivery and postpartum care. They were discharged home without active treatment. One patient was re-admitted postpartum with mild respiratory distress, treated via supportive therapy and discharged. $54.6 \%$ in this group were obese. The cesarean birth rate in the asymptomatic group was $28.6 \%$.

Timing of the patient's first contact with SARS-CoV-2 during pregnancy is very critical to ascertain possible effects of the virus on fetal development and growth, the degree of maternal Covid-19 disease severity and the impact of Covid19 in pregnancy.

Patients SARS-2 positive in the first trimester (conception to the end of week 14)* and the outcomes are listed as follows:

1. Voluntary interruptions of a 12 and a 10-week pregnancy during the course of the study. There was no documented fetal autopsy or fetal organ tissue histology

2. A tubal ectopic pregnancy that was treated surgically with no fetal tissue studies

3. SARS-2 positive at week 14. She was treated and discharged to continue with the pregnancy. Delivered by scheduled repeat cesarean, at week 39 6/7, BW 4015 g. Apgar scores 9 and 9. Large neonate tested SARS-2 negative. Breast feeding. 
4. SARS_CoV-2 positive at 8-week gestation. She recovered and is pregnant going through prenatal care visits. No current evidence of fetal structural anomalies or growth abnormalities. No maternal chronic signs or symptoms of Covid-19 disease.

5. SARS CoV-2 positive at 12 weeks gestation. Treated and discharged. Continue prenatal care. EDD June 2021

Patients SARS-2 positive in the Second trimester, between weeks 15 and $28 *$

1. Patient with history of three previous early spontaneous abortions, experienced a spontaneous abortion at 17 weeks. She was hospitalized for the treatment of retained products of conception. She experienced severe post abortion anxiety and depression. BW $90 \mathrm{~g}$. There was no fetal autopsy and the histology reported advanced tissue autolysis with no pertinent diagnosis

2. Diagnosis with fetal Downs' syndrome $(46 \times y 21+)$ via amniocentesis. Admitted for medical induction at 20 weeks. She delivered vaginally a still born fetus BW $395 \mathrm{~g}$ and declined any studies

3. Diagnosed at 22 weeks, treated, and proceeded with prenatal care. She is undelivered with no chronic signs of maternal disease and normal fetal growth estimation.

4. Short cervix and PPROM at 22 weeks. Delivered vaginally. BW $520 \mathrm{~g}$, Apgar 1/1, followed by neonatal death. Placental histology report acute chorioamnionitis.

5. Diagnosed at 24 weeks, treated, recovered, and discharged. She was delivered elsewhere.

6. Diagnosed at 26 4/7 weeks, was treated and discharged. Lost to follow up.

7. Diagnosed and delivered at $336 / 7$ weeks following unremitting preterm labor with 2 previous cesareans, delivered by uncomplicated repeat cesarean. Tubal ligation. BW 2030 g. Apgar scores 7, 8, 9. Breast feeding. NN SARS-2 negative

8. Diagnosed and Delivered at $262 / 7$ weeks with the diagnosis of intractable bronchial asthma, BMI $58 \mathrm{~K} / \mathrm{m}^{2}$, delivered vaginally, BW 890 g, Apgar 6/9.

9. Diagnosed at 23 weeks, treated, and discharged. Continue prenatal care and was readmitted at 39 weeks for uncomplicated vaginal delivery. BW $4026 \mathrm{~g}$, Apgar 9/9.

10. Diagnosed at 26 6/7 weeks with preeclampsia; was admitted for treatment and delivered by cesarean at 30 weeks $3 / 7$ for preeclampsia with severe features. BW $1200 \mathrm{~g}$, Apgar 4/7/8.

Patients SARS-2 positive in the Third trimester (29 to 42 weeks gestation) *.

1. Three patients were first diagnosed SARS-CoV-2 positive after week $28 *$ and delivered before week 37 (preterm). The time interval between first SARS-2 positive diagnosis and delivery ranges from 0.5 to 5 weeks.

2. Twenty patients were diagnosed SARS-2 positive after 28 weeks and delivered on the index admission. prior to 37 weeks (preterm). One patient was delivered by cesarean at 31 weeks second to deteriorating ARDS second to Covid-19 and needed mechanical ventilation $(0.6 \%)$

3. The remaining of the cohort was diagnosed SARS-2 positive after 28 weeks gestation and delivered during the index admission between week 37 and week 42 weeks (term).

*Williams Obstetrics. Twenty Second Edition. Chapter $8^{\text {th }}$. Mc. Graw Hill Companies Inc.

Seventeen patients experienced premature rupture of membranes (PROM). 7 were preterm $(4.7 \%)$. Ten patients were $>37$ weeks $(6.7 \%)$. The expected frequency of PROM is $2.5 \%$ before 37 weeks and $8 \%$ after 37 weeks. (ACOG PB 277/2020)

We compared the total cesarean birth rate during the same period of time in the 2019 pre-pandemic months. The institution rate averaged $32 \%$. During the same period in 2020 during the pandemic the overall rate averaged $34.4 \%$. No significant difference.

The group of Covid-19 symptomatic patients had a $35.2 \%$ total cesarean delivery rate and the asymptomatic group the total rate was $28.6 \%$.

There were no complications that could be related to Covid-19 during the deliveries or the postpartum period. Timing of the cord clamping was left at the discretion of the delivering clinician given the contradictory current recommendations

Relative lymphocytopenia ( $<20 \%$ lymphocytes) was found in thirty-seven patients $(60.6 \%)$. Relative lymphopenia below $20 \%$ lymphocytes has been reported as a predictive marker for disease severity in non-pregnant patients affected by Covid-19 [5]. We noted no clinical difference in these patients' behavior or clinical outcome. C-reactive protein was determined in eleven randomly selected patients and all demonstrated elevated levels. There was no difference in their clinical behavior or outcome.

24 patients $(15.8 \%)$ delivered prior to 37 weeks. There was no demonstrable Covid-19 associated etiology with the preterm birth. Three of the patients were delivered with the diagnosis of severe preeclampsia with severe features.

There was one maternal readmission second to recurrent symptoms of Covid-19 disease; 5 weeks after her discharge and delivered at 37 weeks vaginally without any complications. There was no requirement for supplemental oxygen. She remained SARS-CoV-2 positive by nasopharyngeal swab.

One patient was readmitted four weeks after her original admission secondary to pulmonary embolism and anticoagulated; she was induced at $373 / 7$ weeks for preeclampsia; delivered vaginally with no complications and discharged on anticoagulants.

There were three Apgar scores less than 5 at one minute, from two patients with severe preeclampsia, and one failed trial of labor after cesarean. Three patients' scores were missing.

Median birth weight was 3440 grams. There were no small for gestational age newborns.

$81 \%$ of patients chose to breast feed and were given verbal 
and written instructions for proper personal protection and hygiene precautions.

Neonates from mothers who tested positive at the delivery admission were tested for SARS-CoV-2 at 24 and 48 hours of life. Four percent tested positive (4\%). Both newborns of the single set of twins were negative for SARS-CoV-2.

All preterm newborns were admitted to the Neonatal ICU as per protocol and were tested twice: once at 24 hours of life, repeated at 48 hours.

In nine patients who had tested SARS-CoV-2 positive during the pregnancy, treated and discharged, tested negative at the time of the delivery admission, neonatal testing was not performed according to local protocol. Two patients declined testing of their newborn.

No newborns were suspected or diagnosed with Covid-19. There were no reported structural congenital anomalies.

$52.6 \%$ patients opted for pain management during labor and received regional epidural analgesia with patientcontrolled adjustments. Spinal anesthesia was administered for scheduled primary or repeat cesareans. In 12 cases no pain control was utilized second to patient refusal or advanced second stage of labor.

Placenta microscopy was obtained in 30 patients $(21.4 \%)$. Pathologists were blinded to the maternal diagnosis. The most common diagnosis was syncytial knotting. No special assessments were conducted in the placenta or the membranes. No specific microscopic findings of maternal vasculopathy were reported and no virions were described [6].

There were no maternal, fetal or neonatal deaths during the study period that could be attributed to the Covid-19 disease.

\section{Conclusions}

\subsection{Our Study}

Previous analysis of the effects of SARS-CoV-1, Middle East Respiratory syndrome (MERS) and other corona virus infections reported that affected pregnant women seem to experience a disproportionately higher rate of disease than those of their non-pregnant peers, and it was proposed that the physiologic changes of pregnancy could be the underlying cause $[7,30]$. It is biologically plausible that virus mutations, changes in angiotensin-converting enzyme-2 polymorphisms or gestational downregulation in Type I lymphocytes and up regulation of Type II lymphocyte concentration with anti-inflammatory capability in the face of the viral infection may provide a plausible explanation for the clinical variation we observed [18]. The information provided by the Michigan Department of Human and Health Services (MDHHS) indicates the presence of up to 5 SARSCoV-2 clades in Michigan, involving small kilobase differences or deletions [19]. However, our knowledge is still incomplete and conflicted.

The strength of our study is based on its limited time of data collection which allowed for only minor adjustments in the clinical approach as the pandemic progressed, given the rapidly evolving knowledge of the novel pathogen characteristics; all patients were treated by a limited number of practitioners. The weaknesses are those associated with limited geographic scope and a single institution experience; possible selection and confounding biases in cohort studies, which we attempted to prevent, and our patient loss was only two cases (1.6\%). We observed the STROBE recommendations while developing the clinical descriptions of the cohort. (Von Elm et al 2014). We report that the predominant characteristic of the symptomatic group of pregnant patients who were confirmed SARS-CoV-2 positive, was that of a mild to moderate Covid-19 disease presentation, with one patient $(0.6 \%)$ showing delayed treatment, had developed severe Covid-19 and required ICU admission and mechanical ventilation.

\subsection{Screening}

The SARS-2 positive patients in the asymptomatic group did not show clinical evidence of Covid-19 disease during the hospital stay. Other reported limited cohorts revealed a significant spectrum of Covid-19 disease severity where 20 to $40 \%$ of patients have mild disease [8-12]. We recommend a widespread provider and population education regarding early recognition of clinical signs and symptoms during pregnancy and early access to clinical evaluation, prospective assessment of clinical risk with low threshold for active treatment. When appropriate, feasible and safe, early transfer the pregnant woman to a higher level of maternal care is also recommended. Screening through a specific questionnaire upon arrival to the hospital (cough, shortness of breath, malaise) including maternal thermal check (fever $38^{\circ} \mathrm{C}$ ), failed to identify $78 \%$ of patients that were laboratory confirmed positive SARS-CoV-2. These potentially presymptomatic or asymptomatic carriers may endanger other family members and caregivers, supporting the use of universal testing. In the USA there has been no standard sanctioned treatment for Covid-19 until October 22, 2020 when the FDA announced their approval of Remdesivir (Veklury $\left.^{\mathrm{TM}}\right)^{30}$ to treat Covid-19 in hospitalized adults. Pregnant and lactating women were excluded from the NIH drug's clinical trial. (ACTT NCT 04280705) [13].

\subsection{Acute Respiratory Distress Syndrome}

Covid-19 is believed to progress to Acute Respiratory Distress Syndrome (ARDS) rapidly in pregnancy [14, 15]. We report that $86 \%$ of patients that tested positive and were followed through the admission, induction of labor, labor, delivery and post-partum period did not develop the respiratory disease while in the hospital or after discharge, as reported through periodic telephone contacts. The patients were provided with written instructions about physical distancing, personal hygiene and quarantine at home, following the recommendations of the CDC. We received no reports of post discharge lingering or recurring effects in the form of a post viral syndrome, residual disease, reinfection or exacerbation (long haul effects). An extended post-partum follow up will be reported separately with the objective of 
defining the presence of post-acute Covid-19 signs.

\subsection{Outcomes Categorized by Ethnicity}

Black women were $32.6 \%$ of the subjects in our cohort. Co-morbidities in Black women were X 1.23 higher than in the second ethnic group, women of Middle East ancestry. There is an urgent need to ascertain the degree to which the patient's age, race and ethnicity, preexisting comorbidities, and access to health care represent a significant increased risk of severe morbidity and mortality associated with Covid-19 in pregnancy [16]. There is also value in understanding the local and regional prevalence and behavior of the disease. $61 \%$ of the study group patients were obese; $81 \%$ of the symptomatic patients were obese and $25 \%$ were morbidly obese. This observation is clinically significant at a time when the prevalence of maternal obesity continues to increase. [17] Expanded demographic studies tailored to the prevalent area ethnicities is important. To our knowledge this is the first study of Covid-19 in pregnancy in the USA that has disaggregated the Middle East population, which in our cohort represented $35.3 \%$ of the study group.

We recognize that our findings may not be generalizable and are different to those reported by other institutions geographically distant from the upper Mid-West USA [2022]; we are challenged by the protean clinical characteristics and behavior of this disease. This issue demands close attention to the individual patient clinical condition and a proactive strict follow up approach, understanding the speed with which maternal respiratory decompensation may occur. This is the first report that disaggregates women of Middle East ancestry as a separate group and the need for understanding health care culture [29].

\subsection{Neonatal Outcomes}

We report $4 \%$ of SARS-CoV-2 positive neonates with no evidence of symptomatic Covid-19 disease. We recommend a more thorough evaluation of the placenta to accurately support or refute the ability of the virus to traverse the placenta filter especially in patients with comorbidities that may affect normal placenta implantation development and function [23]. The chance of in utero Covid-19 disease with presence of neonatal immunoglobulins has been described and deserves further investigation [24, 28].

\subsection{Public Health Implications}

The health care systems' preparedness for the pandemic and its dramatic health care consequences has been less than optimal [25-27]. It is very important that health care and civil authorities work together. The virus pathogenicity is still incompletely understood and accurate information is essential to base decisions that seriously affect the public health. Preparation for a pandemic must be considered and event of national interest and part of the overall national security program. We recommend that state governments consider publishing a full report of the public health and the economic impact of the executive decisions made during the pandemic. The recent approval of the Covid-19 vaccines adds another clinical factor to the care of the pregnant women. Patient acceptance in view of limited knowledge regarding side effects and effectiveness will need to be determined. No pregnant patient received a covid-19 vaccine during the study period.

Timely, accurate and widespread sharing of clinical experiences and perinatal outcomes around the world may assist us in increasing our understanding of the host-pathogen interactions and the variable behaviors of this novel highly significant pathogen. This approach may assist in the planning of accurate, credible and non-conflicting public information, protection of health care personnel and vulnerable populations, patient care, resource utilization and strategic stockpiling.

This research was possible because of the patients whose information is included within the data base.

\section{Acknowledgements}

The authors acknowledge the contribution of Derek Bair M. D Chief of Neonatology and Joyce Grignon RN, BSN, Labor and Delivery Manager who provided information associated with neonatal procedures and general department policies during the time of the study. To A. K. Gullapalli and N. K Chintala for their assistance with access to IT clinical data.

The authors thank the antepartum, labor and delivery, postpartum nursing personnel and attending physicians for their dedication to the care of these patients under very unique circumstances.

The authors report no conflict of interest.

\section{References}

[1] Contini C, Di Nuzzo M, Barp N, et al. The novel zoonotic COVID-19 pandemic: An expected global health concern. $J$ Infect Dev Ctries. 2020; 14 (3): 254-264.

[2] Li X, Zai J, Zhao Q, et al. Evolutionary history, potential intermediate anim4al host, and cross-species analyses of SARS-CoV-2. J Med Virol. 2020; 92 (6): 602-611.

[3] Voto C., Berkner, P, Brenner C. (September 10, 2020) Overview of the pathogenesis and treatment of SARS-CoV-2 for clinicians: a comprehesive literature review. Cureus 12 (9) e10357 DOI 10.7759/cureus.10357.

[4] Society for Maternal-Fetal Medicine, Halscott T, Vaught J, Miller E. Management considerations for pregnant patients with COVID-19. Society for Maternal-Fetal Medicine. https://s3.amazonaws.com/cdn.smfm.org/media/2415/SMFM COVID_Management_of_COVID pos preg patients 7-220.PDF_pdf. Published July 2, 2020. Accessed November 30, 2020 .

[5] Tan L, Wang Q, Zhang D, et al. Lymphopenia predicts disease severity of COVID-19: a descriptive and predictive study. Signal Transduct Target Ther. 2020; 5 (1): 33. 
[6] Ng WF, Wong SF, Lam A, et al. The placentas of patients with severe acute respiratory syndrome: a pathophysiological evaluation. Pathology. 2006; 38 (3): 210-2.

[7] Schwartz DA, Graham AL. Potential Maternal and Infant Outcomes from (Wuhan) Coronavirus 2019-nCoV Infecting Pregnant Women: Lessons from SARS, MERS, and Other Human Coronavirus Infections. Viruses. 2020 Feb 10; 12 (2): 194.

[8] Breslin N, Baptiste C, Gyamfi-Bannerman C, et al. Coronavirus disease 2019 infection among asymptomatic and symptomatic pregnant women: two weeks of confirmed presentations to an affiliated pair of New York City hospitals. Am J Obstet Gynecol MFM. 2020; 2 (2): 100118.

[9] Yan J, Guo J, Fan C, et al. Coronavirus disease 2019 in pregnant women: a report based on 116 cases. Am J Obstet Gynecol. 2020; 223 (1): 111.e111-111. e114.

[10] Tekbali A, Grünebaum A, Saraya A, McCullough L, Bornstein E, Chervenak FA. Pregnant vs nonpregnant severe acute respiratory syndrome coronavirus 2 and coronavirus disease 2019 hospital admissions: the first 4 weeks in New York. Am J Obstet Gynecol. 2020; 223 (1): 126-127.

[11] Della Gatta AN, Rizzo R, Pilu G, Simonazzi G. Coronavirus disease 2019 during pregnancy: a systematic review of reported cases. Am J Obstet Gynecol. 2020; 223 (1): 36-41.

[12] Zahn C. ACOG statement on COVID-19 and pregnancy. American College of Obstetrics and Gynecology. https://www.acog.org/news/news-releases/2020/06/acogstatement-on-covid-19-and-pregnancy. Published June 24, 2020. Accessed August 20, 2020.

[13] U.S. Food and Drug Administration. Fact sheet for health care providers emergency use authorization (EUA) of Veklury ${ }^{\mathrm{TM}}$ (remdesivir). U.S. Food and Drug Administration. https://www.fda.gov/media/137566/download. Published 2020 Accessed June 20, 2020.

[14] Huang C, Wang Y, Li X, et al. Clinical features of patients infected with 2019 novel coronavirus in Wuhan, China. Lancet. 2020; 395 (10223): 497-506.

[15] Schnettler WT, Al Ahwel Y, Suhag A. Severe acute respiratory distress syndrome in coronavirus disease 2019infected pregnancy: obstetric and intensive care considerations. Am J Obstet Gynecol MFM. 2020; 2 (3): 100120.

[16] Pan D, Sze S, Minhas JS, et al. The impact of ethnicity on clinical outcomes in COVID-19: A systematic review. EClinicalMedicine. 2020; 23: 100404.

[17] Scheen AJ. Obesity and risk of severe COVID-19. Rev Med Suisse. 2020; 16 (695): 1115-1119.
[18] Gussow AB, Auslander N, Faure G, Wolf YI, Zhang F, Koonin EV. Genomic determinants of pathogenicity in SARSCoV-2 and other human coronaviruses. Proc Natl Acad Sci U S A. 2020; 117 (26): 15193-15199.

[19] Personal communication, M Soehnlen, Division of Infectious Diseases MDHHS. June 11. 2020. Breslin N, Baptiste C, Miller R, et al. Coronavirus disease 2019 in pregnancy: early lessons. Am J Obstet Gynecol MFM. 2020; 2 (2): 100111.

[20] Liu D, Li L, Wu X, et al. Pregnancy and Perinatal Outcomes of Women with Coronavirus Disease (COVID-19) Pneumonia: A Preliminary Analysis. AJR Am J Roentgenol. 2020; 215 (1): 127-132.

[21] Li N, Han L, Peng M, et al. Maternal and neonatal outcomes of pregnant women with COVID-19 pneumonia: a casecontrol study. Clin Infect Dis. 2020.

[22] Ng WF, Wong SF, Lam A, et al. The placentas of patients with severe acute respiratory syndrome: a pathophysiological evaluation. Pathology. 2006; 38 (3): 210-218.

[23] Pique Regi R, Romero R, Tarca A L, Luca F, Xu Y, Alazizi A et al. Does the human placenta express the canonical cell entry mediators for SARS-CoV-2 ? Elife. 2020 Jul 14, 9: e58716.

[24] Daniels K, Oakeson AM, Hilton G. Steps toward a national disaster plan for obstetrics. Obstet Gynecol. 2014; 124 (1): 154-158.

[25] Committee Opinion No. 726: Hospital Disaster Preparedness for Obstetricians and Facilities Providing Maternity Care. Obstet Gynecol. 2017; 130 (6): e291-e297.

[26] Haeri S, Marcozzi D. Emergency preparedness in obstetrics. Obstet Gynecol. 2015; 125 (4): 959-970.

[27] CDC. Data on COVID-19 during pregnancy: Birth and infant outcomes. https://www.cdc.gov/coronavirus/2019ncov/casesupdates/special-populations/birth-data-on-covid-19.html. Accessed February 10, 2021.

[28] "Lobbying for a 'MENA' category on U.S. Census" Wiltz, Teresea. USA Today. Published 7 October 2014. Accessed 14 February 2021.

[29] Veklury (remdesivir) EUA Letter of Approval, reissued 10/22/2020. Available

Accessed February 2, 2021

[30] Ghi T, di Pasquo E, Mekinian K, Calza L, Frusca T. SarsCoV-2 in pregnancy. Why is it better than expected? European Journal of Obstetrics \& Gynecology and Reproductive biology. 252 (2020): 476-78. 